\title{
The effect of dantrolene sodium in relation to blood levels in spastic patients after prolonged administration
}

\author{
W J MEYLER, ${ }^{*}$ H BAKKER, $\dagger$ J J KOK, $\ddagger$ S AGOSTON, * AND H WESSELING* \\ From the Institute of Clinical Pharmacology, State University Groningen, Groningen, ${ }^{*}$ the Rehabilitation \\ Hospital "De Hoogstraat," Leersum, $\dagger$ and the Rehabilitation Hospital, "Heliomare," Wijk aan Zee, ${ }_{+}$ \\ The Netherlands
}

SUMMARY In 25 patients with spasticity, pharmacokinetics and effects of dantrolene sodium were investigated after prolonged administration. A beneficial effect occurred in seven patients. The results were better on $100 \mathrm{mg}$ daily than on a higher daily dose. An increase of the daily dose from 200 to 400 mg was not associated with higher blood levels. Many side effects were noted such as: anorexia, nausea, drowsiness, depression and muscle weakness. From this study we conclude that dantrolene sodium is a muscle relaxant with a weak to moderate effect in patients with spasticity; the effect at doses higher than $200 \mathrm{mg}$ daily is probably poor.

Dantrolene sodium is a muscle relaxant used in the treatment of spasticity. ${ }^{1-9}$ Though effective in various spastic conditions, reports on its therapeutic usefulness are conflicting and overshadowed by possible drug-related side effects and toxic reactions, ${ }^{8} 1011$

It is not, however, known if such effects are correlated with blood levels and whether failures may be due to insufficient blood levels. The purpose of the present study was not primarily to quantify therapeutic drug effects. Of the patients available for this study most had been treated with various drugs and other therapies. Dantrolene sodium was given in increasing doses to these patients and effects were noted; the main purpose of this study was to collect pharmacokinetic and toxicity data.

\section{Patients and methods}

Twentyseven patients (23 males and four females) with spasticity of various origin entered to study. Their ages ranged from 19 to 68 years (mean of 40.5 years). The spasticity, which was supposed to be stable, was in 22 cases of spinal origin and in five cases of cerebral origin (table 1). Patients with cardiovascular, metabolic and present or past liver diseases were excluded from the study. Spasticity was prominent in 16 patients, disturbance of activity of daily living (ADL) in five patients, nursing difficulties in two, disturbance of motor performance in four, pain in four patients and clonus in one patient.

Dosage Dantrolene sodium (in capsules of 25 and 100

Address for reprint requests: Dr WJ Meyler, Institute of Clinical Pharmacology, 9713 BZ Groningen, The Netherlands

Accepted 30 November 1980 $\mathrm{mg}$ ), was supplied according to the following dosage schedule: $25 \mathrm{mg}$ twice daily, $25 \mathrm{mg}$ four times daily, $50 \mathrm{mg}$ four times daily, $100 \mathrm{mg}$ four times daily, until the "optimal" dose of the drug was achieved, provided the maximum daily dose of $400 \mathrm{mg}$ was not exceeded. The "optimal" daily dose was defined as the dose with which the therapeutic goal was obtained without unacceptable side effects. The speed of dosage titration depended on the individual patient's tolerance of the drug. Patients were kept on a particular dose level for two weeks before the next higher dose was given. Each patient maintained his "optimal" dose till the end of the study. Patients who displayed drug intolerance were dropped from the study. In patients with intercurrent illness, during which dantrolene sodium therapy seemed to be inappropriate, the drug was temporarily discontinued, but it was resumed after recovery.

Base line and follow-up measurements Data were collected before the start of the study, and control measurements were made before and at 14 days intervals during the study. They consisted of: (1) Complete neurologic examination during which resistance against passive

Table 1 Diagnosis in 25 patients. Two patients with spinal cord pathology were omitted from the study, because of slight impairment of liver function

\begin{tabular}{lc}
\hline & Number of patients \\
\hline SPINAL CORD PATHOLOGY & \\
Quadriplegia & 9 \\
Paraplegia & 10 \\
MULTIPLE SCLEROSIS & 1 \\
SUPRASPINAL PATHOLOGY & 2 \\
Hemiplegia & 1 \\
Cerebral palsy & 2 \\
Contusio cerebri & \\
\hline
\end{tabular}




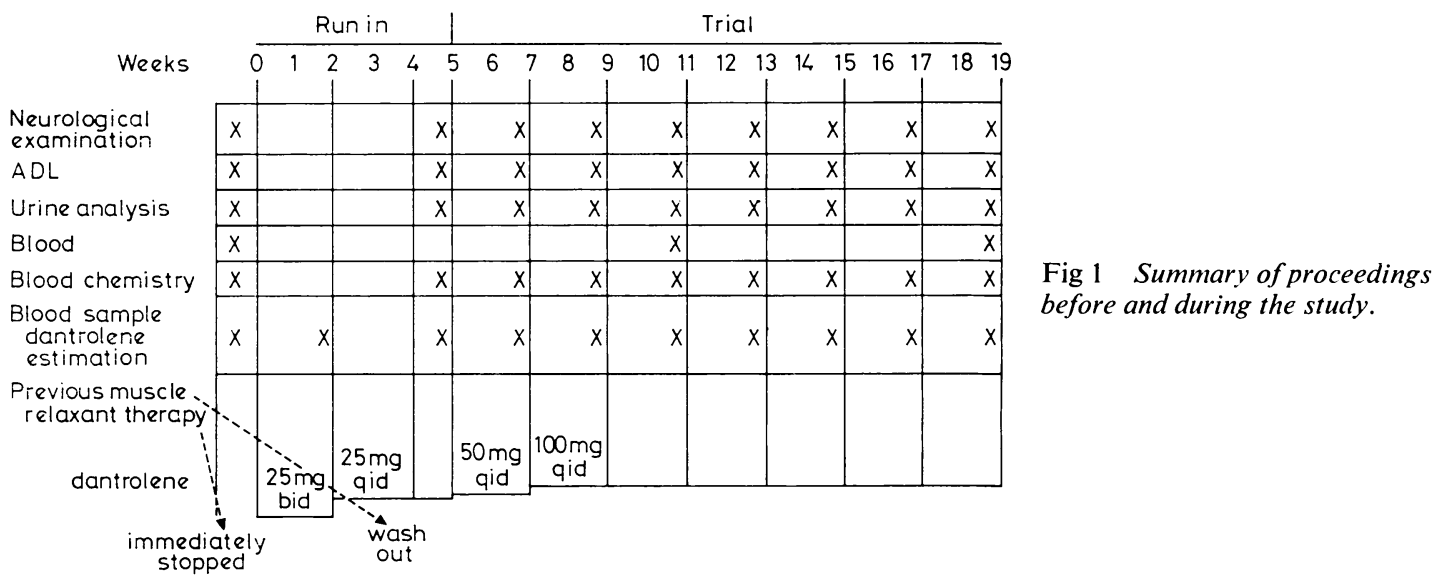

stretch (according to the Ashworth rating scale ${ }^{12}$ ), and strength, clonus and tendon jerk reflexes (according to predetermined rating scales) were measured (2) Activity of daily living (ADL) evaluation, (3) Laboratory observations including checks of haemoglobin, haematocrit, sedimentation rate, white cells, platelets, as well as determination in serum of urea, creatinine, direct and indirect bilirubin, glutamic oxaloacetic transaminase, glutamic pyruvic transaminase, lactic dehydrogenase, and alkaline phosphatase. The urine was analysed for red and white blood cells, casts, protein and glucose. The same follow-up measurements were done before and during the trial at two weeks intervals. The diagram shows the relevant proceedings (fig 1).

A $5 \mathrm{ml}$ blood sample was collected every two weeks approximately three hours after the morning ingestion for the estimation of drug levels. The samples (cells + plasma) were deep-frozen until analysis. Dantrolene sodium, 5-hydroxy dantrolene and the acetylated metabolite were measured according to the method of Hollifield and Conklin. ${ }^{13}$ At the end of the 19 weeks study the "overall clinical result" was evaluated. Any change in spasticity, as judged by the doctor was scored as improved, equal and worse. The blood levels after prolonged administration of dantrolene sodium were compared at different daily doses. Changes (in a set of consistent trends) in spasticity and in side effects were compared with dosage and blood levels of dantrolene sodium. If the patient used other muscle relaxants (diazepam or baclofen), this medication was stopped if possible. Depending on the condition of the patient, such medication was either withdrawn immediately or gradually during the first three weeks (fig 1).

\section{Results}

Because of slightly impaired liver function, two quadriplegic patients were excluded from participation. Seventeen of the 25 patients completed the 19 weeks study, while eight patients had to stop earlier. Three patients stopped because of non-drug related reasons (operation, removal or lack of motivation), Five patients were withdrawn because of intolerable side effects (incontinence 1, muscle weakness 2, pain 2). The minimum duration of participation for all patients was five weeks. The daily dose of the patients with intolerable side effects never exceeded $100 \mathrm{mg}$ per day.

The following data are based on the analysis of 25 patients. In table 2 the data of the neurological examinations are summarised.

In 12 of the 23 patients with increased passive resistance dantrolene sodium gave an improvement (two other patients had muscle spasms not in their limbs, but in the abdominal muscles, which made proper evaluation impossible). Most patients exhibited a decrease of reflex activity and clonus. In contrast with other experiences more patients complained of worsening of involuntary movements and pain.

In seven paretic patients muscle strength improved during the study, while 13 patients showed a more or less distinct improvement of ADL; deterioration of ADL was observed in three patients. It should be

Table 2 Results of dantrolene sodium treatment on various parameters of spasticity in 25 patients

\begin{tabular}{lcccccc}
\hline & $\begin{array}{l}\text { Passive* } \\
\text { resistance }\end{array}$ & Paresis & $\begin{array}{l}\text { Reflex } \\
\text { hyperactivity }\end{array}$ & Clonus* & $\begin{array}{l}\text { Involuntary* } \\
\text { movements }\end{array}$ & $\begin{array}{c}\text { Pain* } \\
\text { Improvement }\end{array}$ \\
No change & 12 & 7 & 20 & 16 & 3 & 5 \\
Deterioration & 8 & 16 & 4 & 1 & 5 & 5 \\
\hline
\end{tabular}

*These symptoms were not present in all patients 
noticed that the regular rehabilitation programme was continued for each patient during the study. It is difficult, therefore, especially as far as muscle strength and ADL functions are concerned, to discriminate between the drug effect and the effect of the other therapeutic measures.

Before the start of the study, 11 patients used a different muscle relaxant (baclofen 4, diazepam 4, baclofen combined with diazepam 3). This medication was eliminated during the first three weeks in 10 patients, while one patient remained on concurrent diazepam medication during the whole study. Table 3 lists the various dose levels that were obtained and the number of corresponding patients. The mean blood levels of dantrolene sodium and 5hydroxydantrolene were determined at each dose level after 14 days of administration. If in those patients, who gradually increased their dose to $400 \mathrm{mg}$ per day, the daily doses are plotted against the blood levels of dantrolene sodium and those of 5-hydroxydantrolene, a linear dose-concentration relationship is found with differences between the corresponding blood levels for the 50,100 and $200 \mathrm{mg}$ daily dose levels, but not between the 200 and $400 \mathrm{mg}$ dose levels. These results are shown in fig 2 . This was found if all patients were included, but also if only those who reached the $400 \mathrm{mg}$ dose were considered, suggesting that possible differences in metabolisers ("slow and fast metabolisers") play no role (fig 3).

The ratio between dantrolene sodium and 5hydroxydantrolene did not change in the course of weeks. After prolonged administration of both 100 and $400 \mathrm{mg}$ daily, blood levels remained fairly constant; approximately $0.7 \mu \mathrm{g} / \mathrm{ml}$ in the patients who remained on the $100 \mathrm{mg}$ dose, but only twice that concentration (approximately $1.4 \mu \mathrm{g} / \mathrm{ml}$ ) in the $400 \mathrm{mg}$ group. The acetylated metabolite was only occasionally detectable, but the detection level was rather high (approximately $0 \cdot 8 \mu \mathrm{g} / \mathrm{ml}$ ). The "overall clinical result" of dantrolene sodium therapy, as judged by the doctor in charge of the patient and the patient himself, is shown in table 4 in relation to the

Table 3 The mean blood level of dantrolene sodium (DS) and 5-hydroxy-dantrolene $(50 \mathrm{HD})$ determined from data of all patients $(n)$ at each level dose. Column 2 indicates the number of patients that remained on the different daily dose levels

\begin{tabular}{lcll}
\hline $\begin{array}{l}\text { Daily dose } \\
\text { level mg }\end{array}$ & No patients & $\begin{array}{l}\text { Mean DS conc } \\
\pm S D(n)(\mu \mathrm{g} / \mathrm{ml})\end{array}$ & $\begin{array}{l}\text { Mean 5OHD conc } \\
\pm S D(n)(\mu \mathrm{g} / \mathrm{ml})\end{array}$ \\
\hline 50 & - & $0.37 \pm 0.29(25)$ & $0.08 \pm 0.08(25)$ \\
100 & 8 & $0.59 \pm 0.21(25)$ & $0.17 \pm 0.11(25)$ \\
150 & 1 & & \\
200 & 6 & $1.08 \pm 0.55(16)$ & $0.44 \pm 0.30(16)$ \\
400 & 10 & $1.44 \pm 0.89(10)$ & $0.51 \pm 0.36(10)$ \\
\hline
\end{tabular}

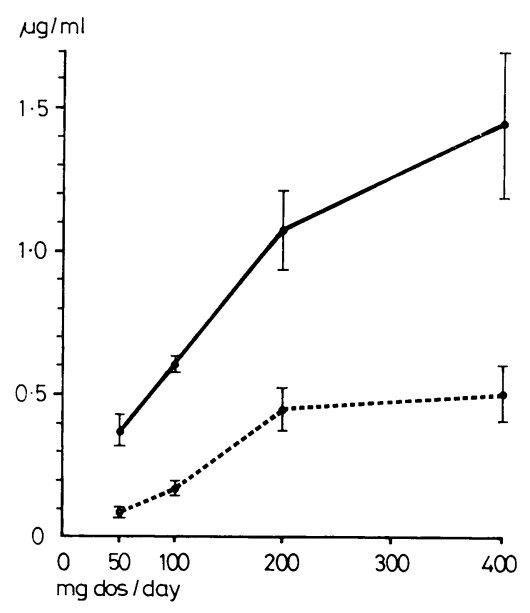

Fig 2 Mean blood levels $( \pm S E M)$ of dantrolene sodium (-) and 5-hydroxy-dantrolene (-) at different daily doses.

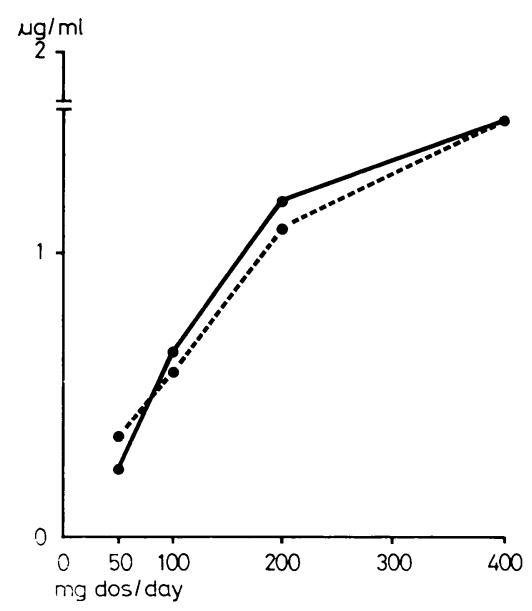

Fig 3 Mean blood levels of dantrolene sodium at different daily dose; $(-)$ all patients $(n=10)$ who reached the maximum dose of $400 \mathrm{mg}$ daily, (-) all patients $(n=25)$ at different dose levels, including the 10 patients who reached $400 \mathrm{mg}$ daily.

Table 4 The "overall clinical result" which was observed in the number of patients with matching blood leveis $( \pm S D)$ of dantrolene sodium (DS) and 5-hydroxydantrolene $(50 \mathrm{HD})$

\begin{tabular}{lcll}
\hline Results & No patients & $\begin{array}{l}\text { Mean DS conc. } \\
\pm S D(\mu \mathrm{g} / \mathrm{ml})\end{array}$ & $\begin{array}{c}\text { Mean } 50 \mathrm{HD} \text { conc. } \\
S D(\mu \mathrm{g} / \mathrm{ml})\end{array}$ \\
\hline Marked & 3 & $1.19 \pm 0.57$ & $0.44 \div 0.30$ \\
Moderate & 4 & $0.66 \pm 0.22$ & $0.16 \div 0.04$ \\
$\begin{array}{l}\text { Slight/ } \\
\text { insufficient }\end{array}$ & 7 & $1.17 \pm 0.54$ & $0.46 \pm 0.24$ \\
Absent & 11 & $1.09 \pm 0.57$ & $0.43 \therefore 0.27$ \\
\hline
\end{tabular}


mean blood levels of dantrolene sodium and 5hydroxydantrolene. No correlation was found between blood level and effect, which indicates that the effect on spasticity after prolonged administration of dantrolene sodium may occur at individually very different blood levels. These results are in accordance with those of a former study, which showed no correlation between plasma concentrations of dantrolene sodium (alone or together with 5-hydroxydantrolene) and the muscle relaxant effect in spastic patients after a single dose of 100 mg. ${ }^{14}$ It should be noticed, however, that the mean blood levels in the group of patients with a moderate effect of dantrolene sodium therapy, are much lower than those in the other three groups. If the daily dose levels between the group with a positive result (marked + moderate) and the group with a negative result (slight/insufficient + absent) are compared (table 5), it is seen that five out of seven patients in the first group remained on $100 \mathrm{mg}$ per day, whereas only one patient received $400 \mathrm{mg}$ per day. In the second group, however, only three out of 17 patients remained on $100 \mathrm{mg}$, while nine patients received the maximum dose of $400 \mathrm{mg}$ per day.

It appears that the results in those patients who received more than $100 \mathrm{mg}$, were significantly worse than in those who remained on a $100 \mathrm{mg}$ daily dose (Fisher exact probability test, $\mathrm{p}<0.01$ ). One may also say that the majority of patients did not react favourably, even at the highest dose levels.

Table 5 The maximum daily dose level of dantrolene sodium and the number of patients with a positive or negative result from medication

\begin{tabular}{lll}
\hline Daily dose level $(\mathrm{mg})$ & Positive no. patients & Negative no. patients \\
\hline 50 & - & - \\
100 & 5 & 3 \\
150 & - & 1 \\
200 & 1 & 5 \\
400 & 1 & 9 \\
\hline
\end{tabular}

Four patients (out of seven), who experienced a beneficial effect from the medication, continued with dantrolene sodium after the study. The other three withdrew: two patients because of disturbing side effects (skin rash, muscle weakness and pain) and one patient, because of disappearance of spasticity. Table 6 lists the side effects that occurred during the study. The total number of these exceeded the number of patients. In most cases the side effects were not transient, since they were observed twice at two week intervals. Table 6 shows the different mean blood vessels and daily dose levels for those side effects that were observed in more than two patients. Though side effects were noticed after different dosages, the concomitant blood levels at which they occurred did not differ (apart from those patients with drowsiness and muscle weakness) from the values found in patients without side effects. It can be seen that in those patients who experienced muscle weakness, this started at relatively low daily dosage and blood levels. Anorexia was frequently seen, but it only occurred at a relatively high daily dosage.

Examination of the blood chemistry and liver functions revealed no abnormalities. Neither deviation of the normal mean values nor rises to pathological values were observed in any individual.

\section{Discussion}

In this open study lasting 19 weeks a muscle relaxant effect of dantrolene sodium, could only be established in seven out of 25 patients. The effect on neurological signs, for example resistance against passive movements and reflex activity, was much more favourable. This implies that these parameters do not give a good reflection of the "overall clinical result," as has been reported by Monster. ${ }^{5}$ It was remarkable that those patients who had a moderate or good effect, belonged mainly to the group of patients who remained on 100 $\mathrm{mg}$ dantrolene sodium per day. In contrast, all

Table 6 Total amount of cases showing side effects. Mean dose level of dantrolene sodium and mean blood levels of dantrolene sodium $(D S)$ and 5-hydroxydantrolene $(50 H D) \pm S D$ are given for those side effects that were recorded more than twice

\begin{tabular}{|c|c|c|c|c|}
\hline Side effects & No of observations & $\begin{array}{l}\text { Mean dailv dose level } \\
\pm S D(\mathrm{mg})\end{array}$ & $\begin{array}{l}\text { Mean conc } D S \\
\pm S D(\mu \mathrm{g} / \mathrm{ml})\end{array}$ & $\begin{array}{l}\text { Mean conc } 5 O H D \\
\pm S D(\mu g / m l)\end{array}$ \\
\hline Dry mouth & 2 & & & \\
\hline Anorexia & 7 & $300 \pm 129$ & $1 \cdot 26 \pm 0.52$ & $0.42 \pm 0.23$ \\
\hline Nausea & 4 & $233 \pm 153$ & $1 \cdot 10 \pm 0 \cdot 59$ & $0.59 \pm 0.32$ \\
\hline Pyrosis & 1 & - & - & - \\
\hline Incontinence & 2 & - & - & - \\
\hline Obstipation & 1 & - & - & - \\
\hline Impotency & 1 & - & - & - \\
\hline Drowsiness & 6 & $216 \pm 147$ & $0.62 \pm 0.56$ & $0.33 \pm 0.27$ \\
\hline Depression & 3 & $233 \pm 153$ & $1 \cdot 22 \pm 0 \cdot 70$ & $0.53 \pm 0.29$ \\
\hline Muscle weakness & 4 & $112 \pm 25$ & $0.65 \pm 0.54$ & $0.17 \pm 0.09$ \\
\hline Skin rash & 1 & - & - & 一 \\
\hline
\end{tabular}


patients (except one) who achieved $400 \mathrm{mg}$ per day, had insufficient or no beneficial effect from dantrolene sodium therapy. The reason that patients who received $400 \mathrm{mg}$ daily doses did worse than patients who remained on $100 \mathrm{mg}$, may be that the first category suffered from a type of dantrolene sodium resistant spasticity that will not respond to any dose.

The relatively low blood levels after high doses may partly be an explanation. It should also be noticed that the blood levels of dantrolene sodium after $400 \mathrm{mg}$ per day, given for a longer period, did not differ from plasma levels after a $100 \mathrm{mg}$ single dose $\left(1 \cdot 44 \pm 0.89 \mu \mathrm{g} / \mathrm{ml}\right.$ versus $\left.1 \cdot 24 \pm 0.32 \mu \mathrm{g} / \mathrm{ml}^{14}\right)$. There are several possible causes of this phenomenon. Induction of the metabolising enzymes in the liver is not a likely explanation, since the ratio between dantrolene sodium and metabolites did not show a significant change after prolonged administration. A small decrease of this ratio between the second and fifth week is probably due to the difference in half lives. ${ }^{14}$ An increase of rate of metabolism can not explain the lower blood levels, because then this should not only be observed in the highest dose range. If the metabolism of dantrolene sodium follows Michaelis-Menten kinetics, as may be assumed, the velocity of the process will increase with increasing substrate concentrations till metabolising enzyme is saturated; thereafter the opposite phenomenon will occur, resulting in a non-linear increase of plasmaconcentrations. Thus, a different cause, not related to changes in metabolism, is more likely, that is capacity-limited absorption or capacitylimited protein binding. One of the aims of the present investigations was to study any relationship between dose and blood level on the one hand and frequency, duration and severity of changes in liver functions on the other. We were prompted to study this by several reports of hepatic damage, including fatalities. that were possibly caused by dantrolene sodium. ${ }^{15-18}$ In several other studies past reports of changes in liver functions. ${ }^{119-2138}$ Utili $^{11}$ suggested that this complication is only restricted to the higher dose level group. During 19 weeks of treatment we did not observe any abnormality of liver function nor even values that tended to rise. This may be due to the small number of patients participating in the study, but also it indicates that, if this phenomenon occurs, its incidence is not very high.

Many side effects were found in this study. Especially frequent were anorexia and nausea, muscle weakness and drowsiness. These were not transient, except in a few cases. Muscle weakness in two patients was disturbing enough to withdraw them from the medication. Drowsiness and muscle weakness were also reported by others to be major side effects. ${ }^{8-10} 21-24$ Schmidt et al, ${ }^{9}$ who treated
42 patients with spasticity due to multiple sclerosis with maximum dose levels of $300 \mathrm{mg}$ per day, found these side effects, also at low dose levels, in contrast with diazepam. We found that muscle weakness and drowsiness appeared at lower blood levels of dantrolene sodium than the other side effects such as anorexia.

Patients who are easily sedated or patients with borderline strength, may be especially susceptible to these two side effects. As far as the other side effects are concerned, it is suggestive that depression occurring in three patients was drug related, since it disappeared after discontinuation of dantrolene sodium. This also happened to the patient who experienced a skin rash, which was also reported by Joynt ${ }^{23}$ in two patients.

We conclude from our study that under uncontrolled conditions dantrolene sodium is a muscle relaxant with a weak to moderate effect in patients with spasticity; the effects at doses higher than 200 mg daily are probably poor; many side effects were registered, but we could not find any influence on liver functions.

This study was supported by a grant from Norwich Benelux BV and Eaton Laboratories who also performed the analysis of dantrolene sodium. We thank Mrs J H Hettema for typing the manuscript.

\section{References}

1 Chyatte SB, Birdsong JH. The use of dantrolene sodium in disorders of the nervous system. South Med J 7, 830, 1971; 64:

2 Chyatte SB, Birdsong JH, Bergman BA. The effect of dantrolene sodium on spasticity and motor performance in hemiplegia. South Med J 1971; 64:2, 180-5.

3 Chipman M, Kaul S, Lambie M. Efficacy of dantrolene sodium in the tratment of spasticity. Dis Nerv Sys 1974; 427-31.

4 Chyatte SB, Birdsong JH, Bergman DL. Dantrolene in athetoid cerebral palsy. Arch Phys Med Rehabil 1973; 54:365.

5 Monster AW. Spasticity and the effect of dantrolene sodium. Arch Phys Med Rehabil 1974; 55:373.

6 Haslam RHA, Walcher R, Lietman PS, Kallman $\mathrm{CH}$, Mellits ED. Dantrolene sodium in children with spasticity. Arch Phys Med Rehabil 1974; 55.

7 Denhoff E, Feldman S, Litchman H. Efficacy of dantrolene sodium suspension in spastic cerebral palsy. Neurology (Minneap) 1975; 17: 392.

8 Gelenberg AJ, Poskanzer DC. The effect of dantrolene sodium on spasticity in multiple sclerosis. Neurology (Minneap) 1973; 23:12, 1313.

9 Schmidt RT, Lee RH, Spehlmann R. Comparison of dantrolene sodium and diazepam in the treatment 
of spasticity. J Neurol, Neurosurg, Psychiatry 1976; 39:350.

10 Johnson B, Ladd H, Afzelius-Frisk I, LindbergBroman AM, The effect of dantrium on spasticity in hemiplegic patients. Acta Neurol Scand 1975; 51:385.

11 Utili R, Boitnott JK, Zimmerman HJ, Dantroleneassociated hepatic injury. Gastroenterology 1977; $72: 610$.

12 Ashworth B. Preliminary trial of carisoprodol in multiple sclerosis. Practitioner 1964; 192: 540.

13 Hollifield RD, Conklin JD. Determination of dantrolene in biological specimens containing drugrelated metabolites. J Pharm Sci 1973; 62:271.

14 Meyler WJ, Mols-Thurkow I, Wesseling H. The relationship between plasmaconcentrations and the effect of dantrolene sodium in man. Eur J Clin Pharmacol 1979; 16:203-9.

15 Ogburn RM, Myers RL, Burdick GE. Hepatitis associated with dantrolene sodium. Ann Intern Med 1976; 84:1, 53.

16 Schneider R, Mitchell D. Dantrolene hepatitis. JAMA 1976; 235:1590.

17 Goodman CR, Beckman J, Carlson R. Death associated with dantrolene sodium. NY State J Med 1977; 77: 11, 1759.

18 Lundin SR, Uden DL, Hanson RF. Dantroleneassociated hepatitis. Drug Intell Clin Pharm 1977; $11: 279$.

19 Mayer N, Mecomber SA, Herman R. Treatment of spasticity with dantrolene sodium. Am J Phys Med 1973; 52:1, 18.

20 Chyatte SB, Basmaijan JV. Dantrolene sodium: long term effects in severe spasticity. Arch Phys Med Rehabil 1973; 54:311.

21 Knutsson, E, Martensson A. Action of dantrolene sodium in spasticity with low dependence on fusimotor drive. J Neurol Sci 1976; 29:195.

22 Lietman PS, Haslam RHA, Walcher JR. Pharmacology of dantrolene sodium in children. Arch Phys Med Rehabil 1974; 55:388.

23 Joynt RL. Dantrolene sodium: Long term effects in patients with muscle spasticity. Arch Phys Med Rehabil 1976; 57:212.

24 Levine MC, van Brocklin JD. Lioresal treatment of spasticity: a double blind comparison study with dantrolene and diazepam. Neurology (Minneap) $1977 ; 27: 391$. 